\title{
Diferentes substratos e ambientes protegidos para o crescimento de mudas de maracujazeiro amarelo doce
}

\author{
Isabela Machado de Oliveira Lima ${ }^{1}$, Joaquim Souto Silva Júnior ${ }^{1}$, Edilson Costa ${ }^{1}$, Eliana \\ Duarte Cardoso $^{1}$, Flávio Ferreira da Silva Binotti ${ }^{1}$, Marçal Henrique Amici Jorge ${ }^{2}$

\begin{abstract}
${ }^{1}$ Universidade do Estado de Mato Grosso, Unidade Universitária de Cassilândia, Cassilândia, MS, Brasil. E-mail: isabelamachado.oliveira@hotmail.com, souto.agronomia@gmail.com, mestrine@uems.br, elianaduarte@uems.br, binotti@uems.br

${ }^{2}$ Empresa Brasileira de Pesquisa Agropecuária - Embrapa Hortaliças, Brasília, DF, Brasil. E-mail: marcal.jorge@embrapa.br
\end{abstract}

Recebido: 05/09/2016; Aceito: 28/09/2016

\section{RESUMO}

A muda de alta qualidade, com vigor superior e equilíbrio de crescimento em altura e diâmetro, possui condições de melhor pegamento e sobrevivência no local definitivo de plantio. Objetivou-se estudar vários substratos em ambientes telados na formação de mudas de maracujá. Foram utilizados o (A1) telado agrícola (dimensões: 8,0 m x $18,0 \mathrm{~m} \times 3,5 \mathrm{~m}$ ), fechamento em $45^{\circ}$ de inclinação, com tela preta de monofilamento em toda sua extensão, malha para $50 \%$ de sombreamento $\left(\right.$ Sombrite $^{\circledR}$ ) e (A2) telado agrícola (dimensões: 8,0 m x 18,0 m x 4,0 m), com tela aluminizada termorrefletora na cobertura a $3,30 \mathrm{~m}$, malha para $50 \%$ de sombreamento (Aluminet ${ }^{\circledR}$ ), fechamentos laterais e frontais em $90^{\circ}$ de inclinação com tela de monofilamento preta, malha para $50 \%$ de sombreamento. No interior dos ambientes protegidos, as mudas foram formadas em 13 substratos (S) oriundos das combinações (\%) de esterco bovino (E), solo de barranco (S), Bioplant ${ }^{\circledR}(B)$, vermiculita super fina (F) e areia (A). Foram avaliadas a emergência, a altura, o diâmetro do colo e a relação entre a altura e o diâmetro. As melhores mudas de maracujazeiro amarelo doce foram formadas em substratos com maiores quantidade de esterco e/ou vermiculita, com menores quantidades de areia e Bioplant ${ }^{\circledR}$. Substratos com elevadas quantidades de Bioplant ${ }^{\circledR}$ ou areia não são indicados à formação de mudas de maracujazeiro. O telado aluminizado propiciou condições para obtenção de mudas de maior qualidade, com maior diâmetro em alguns substratos, e menor relação altura/diâmetro.

Palavras-chave: Esterco bovino, solo de barranco, Bioplant ${ }^{\circledR}$, vermiculita super fina, areia, telados.

\section{Different substrates and protected environment for the growth of sweet yellow passion fruit seedlings}

\begin{abstract}
A high quality seedling, with vigor superior and balance between growth in height and diameter, may have better survival conditions in the field. The objective was to study different substrates and protected environment on the formation of sweet yellow passion fruit seedlings. The protected environments (agricultural nursery) used were the (A1) agricultural screened (dimensions: $8.0 \mathrm{~m} \mathrm{x} 18.0 \mathrm{~m} \mathrm{x} 3.5 \mathrm{~m}$ ), closing at $45^{\circ}$ tilt, with monofilament black screen throughout its length, mesh with $50 \%$ shading $\left(\right.$ Sombrite $^{\circledR}$ ) and (A2) agricultural screened (dimensions: 8.0 $\mathrm{m} \times 18.0 \mathrm{~m} \times 4.0 \mathrm{~m}$ ), with aluminized thermal reflector screen in coverage at $3.30 \mathrm{~m}$, mesh to $50 \%$ shading (Aluminet ${ }^{\circledR}$ ), side and front closings at $90^{\circ}$ tilt, with black monofilament screen mesh for $50 \%$ shading. Inside the environments, the seedlings were formed on 13 substrates (S) from combinations (\%) of cattle manure (E), soil (S), Bioplant $^{\circledR}(\mathrm{B})$, super fine vermiculite (F) and sand (A). Emergence, height, stem diameter and the relationship between height and diameter were evaluated. The best passion fruit seedlings were formed on substrates having larger quantity of cattle manure and/or vermiculite, with smaller amounts of sand and Bioplant ${ }^{\circledR}$. Substrates with high amounts of Bioplant ${ }^{\circledast}$ or sand are not indicated the formation of passion fruit seedlings. The aluminized greenhouse propitiated conditions for obtaining higher quality seedlings with larger diameter in some substrates, and lower height/diameter ratio.
\end{abstract}

Key words: Cattle manure, soil, Bioplant ${ }^{\circledR}$, super fine vermiculite, sand, screens. 


\section{Introdução}

A muda de alta qualidade, com vigor superior e equilíbrio entre o material da parte aérea e do sistema radicular possui condições de melhor pegamento e sobrevivência no local definitivo de plantio. Esta qualidade elevada se relaciona com sua capacidade de adaptação às condições edafoclimáticas da região quando levada a campo, tais como o clima, o relevo, a litologia, a temperatura, a umidade do ar, a radiação solar, o tipo de solo, o vento, a composição atmosférica e a precipitação pluvial.

Para produção de uma muda de elevada qualidade vários fatores estão envolvidos, tais como qualidade e sanidade das sementes, manejo da produção, irrigação, adubação, e tecnologias como tipos de substratos, tipos de recipientes, tipos e características de ambientes protegidos. Tipos de substrato para produção de mudas de maracujazeiro (Passiflora edulis Sims f. flavicarpa Deg.) foram estudados por diversos autores (VERDIAL et al., 2000; OLIVEIRA et al., 1993; BIASI et al., 1995; SILVA et al., 2001; ALMEIDA, 2003; NEGREIROS et al., 2004; MENDONÇA et al., 2004; PIO et al., 2004; MENDONÇA et al., 2005; RIBEIRO et al., 2005; MENDONÇA et al., 2006; WAGNER JÚNIOR et al., 2006; COSTA et al., 2009; COSTA et al., 2010a; COSTA et al., 2010b; SILVA et al., 2010; COSTA et al., 2011). Estes estudos forneceram dados e informações de várias matérias primas para composição de substratos que permitiram a obtenção de mudas de elevada qualidade.

O uso do esterco bovino, vermiculita, areia e solo, adubados ou não como material de substrato, foram estudados por vários pesquisadores na formação de mudas de maracujazeiro. Verdial et al. (2000) verificaram que o uso de terra adubada e misturada com esterco de curral curtido, com fertirrigação uma vez por semana, promoveram excelente desenvolvimento radicular assim como o uso de casca de pinus e vermiculita em sistema "floating" propiciou as melhores altura da planta; matéria seca da parte aérea e matéria seca da parte radicular de mudas de maracujazeiro. Pio et al. (2004) relatam que o uso de misturas de terra:areia:esterco $(1: 1: 1 \mathrm{v} / \mathrm{v} ; 2: 1: 1 \mathrm{v} / \mathrm{v})$ propiciaram as melhores mudas de maracujazeiro e que a adição de matéria orgânica em formulações de substratos até $1 / 3 \mathrm{da}$ quantidade total é viável, contudo o uso de areia pura ou em mistura com terra não foi um substrato adequado para produção das mudas.

Estudos com substrato comercial Plantmax ${ }^{\circledR}$ puro e/ou em mistura com esterco, solo e vermiculita têm propiciado mudas de maracujazeiro de elevada qualidade. Oliveira et al. (2003) observaram que o uso de Plantmax $^{\circledR}$ e do substrato composto por areia, vermiculita, estéreo (1:1:1), suplementado com $10 \mathrm{~kg} \mathrm{~m}^{-}$ 3 de superfosfato simples, $6 \mathrm{~kg} \mathrm{~m}^{-3}$ de cloreto de potássio, $2 \mathrm{~kg} \mathrm{~m}^{-3}$ de ureia e $8 \mathrm{~kg} \mathrm{~m}^{-3}$ de calcário promoveram maior porcentagem de germinação e adequado desenvolvimento das mudas de maracujazeiro. Silva et al. (2001) observaram que o substrato comercial Plantmax ${ }^{\circledR} 3 / 4$ à base de vermiculita mais casca de Pinus sp (Plantmax ${ }^{\circledR}$ - eucalipto) foi superior à vermiculita na formação das mudas de maracujazeiro; ambos os substratos suplementados ou não com fontes orgânicas [húmus, esterco de curral e Nutriplanta $^{\circledR}$ (produto à base de bactérias)]. O uso de Plantmax ${ }^{\circledR}$, esterco de curral, solo e areia $(1: 1: 1: 1 \mathrm{v} / \mathrm{v})$ promoveram mudas de qualidade (NEGREIROS et al., 2004). Mendonça et al. (2004) comparando os substratos "Plantmax ${ }^{\circledR}+$ areia + solo na proporção 1:1:2 v/v" e "esterco de curral + casca de café + carvão vegetal + areia + solo na proporção de 1:1:1:1:2 v/v", ambos suplementados ou não com Osmocote ${ }^{\circledR}$ (15-1010): $3 ; 6 ; 9$ e $12 \mathrm{~kg} \cdot \mathrm{m}^{-3}$, verificaram que Osmocote ${ }^{\circledR}$ proporcionou mudas de maracujazeiro de melhor qualidade e as misturas de substratos não apresentaram diferenças. Silva et al. (2010) relataram que o substrato formado por "solo + esterco + Plantmax ${ }^{\circledR}$ " favoreceram todos os parâmetros de crescimento do maracujazeiro.

Em relação à ambiência vegetal, estudos foram realizados comparando diferentes configurações e coberturas de ambientes protegidos na formação de mudas de maracujazeiro (MENDONÇA et al., 2005; ZANELLA et al., 2006; COSTA et al., 2009; COSTA et al., 2010a; COSTA et al., 2010b; COSTA et al., 2011). Zanella et al. (2006) testando níveis de sombreamento $(0 \% ; 30 \%$; $50 \%$ e $80 \%)$ com tela preta, na formação de mudas de maracujazeiro, verificaram que a exposição a pleno sol foi prejudicial às mudas e os níveis de sombreamento de $50 \%$ e $80 \%$ foram os mais favoráveis ao crescimento.

Costa et al. (2009, 2010a) testando 4 tipos de ambientes protegidos de estrutura de madeira, verificaram que os telados com telas de cor preta e aluminizado, tanto na cobertura como nos fechamentos laterais em $90^{\circ}$ de inclinação (dimensões: 5,0 m x 5,0 m x 2,5 m), promoveram melhores mudas de maracujazeiro que a estufa agrícola coberta com filme plástico de polietileno e fechamento em $90^{\circ}$ com tela preta (dimensões: 5,0 m x 5,0 m x 2,5 m e altura de 3,3 $\mathrm{m}$ no centro) e que o viveiro coberto com palha de buriti (3,0 m x 1,2 m x 1,7 m) e sem fechamento lateral.

Costa et al. (2010b) testando seis tipos de ambientes protegidos de estrutura de madeira ou de aço galvanizado, verificaram que a estufa agrícola coberta com filme plástico de polietileno e tela aluminizada sob o filme e fechamento em $90^{\circ}$ com tela preta (dimensões: $8,0 \mathrm{~m} \times 18,0 \mathrm{~m} \times 4,0 \mathrm{~m}$ e altura de 6,5 m no centro) de estrutura de aço galvanizado, o viveiro telado de tela preta na cobertura e nos fechamentos laterais em $45^{\circ}$ de inclinação (dimensões: 8,0 m x 18,0 m x 3,5 m) de 
estrutura de aço galvanizado e o viveiro de madeira coberto com palha de buriti (3,0 m x 1,2 m x 1,7 m) propiciaram maior acúmulo de biomassa em mudas de maracujazeiro que os telados de estrutura de madeira cobertos de telas preta e aluminizada e fechamentos laterais em $90^{\circ}$ de inclinação (dimensões: 5,0 m x 5,0 m x 2,5 m) e estufa agrícola de estrutura de madeira coberta com filme plástico de polietileno e fechamento em $90^{\circ}$ com tela preta (dimensões: 5,0 m x 5,0 m x 2,5 $\mathrm{m}$ e altura de $3,3 \mathrm{~m}$ no centro).

Costa et al. (2011) testando 3 tipos de ambientes protegidos de estrutura de aço galvanizado, verificaram que a estufa agrícola coberta com filme plástico de polietileno e tela aluminizada sob o filme a $4,0 \mathrm{~m}$ e fechamento em $90^{\circ}$ com tela preta (dimensões: $8,0 \mathrm{~m} \mathrm{x}$ $18,0 \mathrm{~m} \times 4,0 \mathrm{~m}$ e altura de 6,5 $\mathrm{m}$ no centro) propiciaram melhores mudas de maracujazeiro que os telados com telas de cor preta e aluminizado, tanto na cobertura como nos fechamentos laterais em $45^{\circ}$ de inclinação (dimensões: 8,0 m x 18,0 m x 3,5 m).

Não se verificou na literatura estudo com o substrato comercial Bioplant ${ }^{\circledR}$ na formação de mudas de maracujazeiro, assim como a comparação entre telado com tela preta na cobertura e fechamento com $45^{\circ}$ de inclinação e telado com tela aluminizada na cobertura e tela preta no fechamento em $90^{\circ}$ de inclinação. Diante do exposto, objetivou-se estudar vários substratos contendo diferentes misturas de esterco bovino, solo de barranco, Bioplant ${ }^{\circledR}$, vermiculita super fina e areia fina e telados na formação de mudas de maracujá.

\section{Material e Métodos}

Os experimentos com diferentes substratos e ambientes protegidos para o crescimento de mudas de maracujazeiro foram conduzidos na Universidade Estadual de Mato Grosso do Sul (UEMS), Unidade Universitária de Cassilândia-MS, no período de agosto a outubro de 2015. O local possui latitude de $19^{\circ} 07^{\prime} 21^{\prime \prime} \mathrm{S}$, longitude de $51^{\circ} 43^{\prime} 15^{\prime}$ W e altitude de $516 \mathrm{~m}$ (Estação automática CASSILANDIA-A742). De acordo com a classificação climática de Köppen, apresenta clima tropical chuvoso (Aw).

No interior dos ambientes protegidos, as mudas foram formadas em sacos de polietileno preto $(15,0 \mathrm{x}$ $25,0 \mathrm{~cm}$ ), com capacidade de 1,8 litros. Estes recipientes foram preenchidos com 13 substratos (S1 a S13) oriundos das combinações (\%) de esterco bovino (E), solo de barranco (S), Bioplant ${ }^{\circledR}(B)$, vermiculita super fina (F) e areia (A) (Tabela 1).

Por não haver repetições dos ambientes de cultivo (tipos de telados), cada um foi considerado um experimento. Para cada ambiente de cultivo foi adotado o delineamento experimental inteiramente casualizado para avaliação dos substratos, com 5 repetições de 5 mudas cada. Os ambientes foram avaliados pela análise de grupos de experimentos (BANZATTO; KRONKA, 2013).

Foram utilizados dois tipos de ambientes protegidos de estrutura de aço galvanizado: (A1) - telado agrícola, de estrutura em aço galvanizado, possuindo $8,00 \mathrm{~m}$ de largura por 18,00 $\mathrm{m}$ de comprimento e 3,50 $\mathrm{m}$ de altura, fechamento em $45^{\circ}$ de inclinação, com tela preta de monofilamento em toda sua extensão, malha com $50 \%$ de sombreamento (Sombrite ${ }^{\circledR}$ ); (A2) - telado aluminizado, de estrutura em aço galvanizado, possuindo $8,00 \mathrm{~m}$ de largura por $18,00 \mathrm{~m}$ de comprimento e altura de 4,0 m, com tela aluminizada termorrefletora na cobertura a $3,30 \mathrm{~m}$, malha para $50 \%$ de sombreamento (Aluminet ${ }^{\circledR}$ ), fechamentos laterais e frontais em $90^{\circ}$ de inclinação com tela de monofilamento preta, malha para $50 \%$ de sombreamento. As inclinações de $45^{\circ}$ (A1) e $90^{\circ}$ (A2) das telas laterais são especificações construtivas dos ambientes protegidos utilizados pelas empresas especializadas.

Tabela 1. Substratos (S1 a S13) oriundos de misturas em diversas proporções de esterco bovino (E), solo de barranco (S), Bioplant ${ }^{\circledR}$ (B), vermiculita super fina (F) e areia (A).

\begin{tabular}{|c|c|c|c|c|c|}
\hline & $\begin{array}{c}\text { Esterco Bovino } \\
(\mathrm{E})\end{array}$ & $\begin{array}{c}\text { Solo de Barranco } \\
(\mathrm{S})\end{array}$ & $\begin{array}{c}\text { Bioplant }^{\circledR} \\
\text { (B) }\end{array}$ & $\begin{array}{c}\text { Vermiculita } \\
\text { superfina }(F)\end{array}$ & $\begin{array}{c}\text { Areia } \\
\text { (A) }\end{array}$ \\
\hline $\mathrm{S} 1$ & 50 & 30 & 10 & 10 & 0 \\
\hline $\mathrm{S} 2$ & 40 & 30 & 10 & 10 & 10 \\
\hline $\mathrm{S} 3$ & 30 & 30 & 10 & 10 & 20 \\
\hline $\mathrm{S} 4$ & 20 & 30 & 10 & 10 & 30 \\
\hline S5 & 10 & 30 & 10 & 10 & 40 \\
\hline S6 & 50 & 30 & 10 & 0 & 10 \\
\hline S7 & 30 & 30 & 10 & 20 & 10 \\
\hline S8 & 20 & 30 & 10 & 30 & 10 \\
\hline S9 & 10 & 30 & 10 & 40 & 10 \\
\hline S10 & 50 & 30 & 0 & 10 & 10 \\
\hline $\mathrm{S} 11$ & 30 & 30 & 20 & 10 & 10 \\
\hline $\mathrm{S} 12$ & 20 & 30 & 30 & 10 & 10 \\
\hline $\mathrm{S} 13$ & 10 & 30 & 40 & 10 & 10 \\
\hline
\end{tabular}


As sementes foram adquiridas em comércio local na cidade de Cassilândia-MS. A semeadura foi realizada no dia 12/08/2015, com duas sementes por recipiente, a uma profundidade de 1 a $3 \mathrm{~cm}$. Posteriormente, foi realizado o desbaste, deixando apenas uma planta por recipiente. A emergência de plântula foi verificada no dia 25/08/2015 tendo início aos 13 dias após a semeadura (DAS). Foram realizadas apenas análise não destrutivas das mudas, tais como emergência, altura da muda, diâmetro do colo e relação entre a altura e o diâmetro.

De 25 de agosto de 2015 a 02 de setembro de 2015 foram coletados dados para análise do índice de velocidade de emergência (IVE). Observou-se elevada quantidade de plantas emergidas num curto espaço de tempo, processou-se rapidamente a estabilização de plantas emergidas em um dos tratamentos e encerrou-se a contagem.

Aos 35 (AP1) e 50 (AP2) DAS foram coletados dados da altura de planta (AP) com o auxílio de uma régua milimetrada. $\mathrm{O}$ diâmetro do colo (DC) foi mensurado com paquímetro digital aos 50 DAS. Aos 50 DAS determinou-se também a relação entre a altura da muda e o seu diâmetro do colo (RAD).

O esterco bovino foi adquirido do frigorífico local, fazendo parte de sua composição esterco de curral e material do rumem, sendo compostado por 30 dias, homogeneizado, secado, peneirado, caracterizado quimicamente e fisicamente (Tabela 2). O solo foi coletado na Unidade Universitária de Cassilândia-MS, peneirado, caracterizado quimicamente e fisicamente (Tabela 3). O Bioplant ${ }^{\circledR}$, a vermiculita e a areia fina lavada foram adquiridas de empresas comerciais. $\mathrm{O}$
Bioplant $^{\circledR}$, segundo o fabricante, possui em sua composição fibra de coco, casca de pinus, esterco, serragem, vermiculita, casca de arroz, cinza, gesso agrícola, carbonato de cálcio, magnésio, termofosfato magnesiano (yoorin) e aditivos (fertilizantes).

No interior do ambiente protegido foram monitoradas a temperaturas do ar $\left({ }^{\circ} \mathrm{C}\right)$, a umidade relativa do ar $(\%)$, a radiação solar global $\left(\mathrm{W} \mathrm{m}^{-2}\right)$, a radiação fotossinteticamente ativa total e difusa $(\mu \mathrm{mol}$ $\mathrm{m}^{-2} \mathrm{~s}^{-1}$ ), e a porcentagem de sol horária (\%). Os dados micrometeorológicos no interior do ambiente protegido (Aluminet $^{())}$foram realizadas por sensores específicos, acoplados a um "datalloger" marca Delta T Devices, modelo GP2, instalados no centro geométrico do ambiente. O sistema foi programado para realizar leituras em intervalos de 10 segundos, com médias a cada minuto. Para as radiações, a média diária foi calculada no horário das 8 à 17 horas. Os dados micrometeorológicos estão explicitados na Figura 1 (1a, 1b, 1c, 1d, 1e, 1f) e Tabela 4.

Para o ambiente externo os valores de temperatura do ar, umidade relativa do ar e radiação solar global foram obtidos da plataforma automática de coleta de dados de Cassilândia (A742, INMET-SONABRA), que não fornece as radiações fotossinteticamente ativa (Figura 1; Tabela 2). A quantidade de chuvas que ocorreu no período do experimento foi de $84,40 \mathrm{~mm}$ (A742, INMET-SONABRA).

Os dados foram submetidos à análise de variância (teste F) e as médias comparadas pelo teste de ScottKnott para os substratos e pelo teste " $\mathrm{t}$ " de Student para os recipientes, ambos a $5 \%$ de probabilidade, com o software Sisvar.

Tabela 2. Resultado da análise das características do esterco (E) utilizado. Cassilândia-MS, 2015.

\begin{tabular}{|c|c|c|c|c|c|c|c|}
\hline $\mathrm{N}$ & $\mathrm{P}_{2} \mathrm{O}_{5}$ & $\mathrm{~K}_{2} \mathrm{O}$ & $\mathrm{Ca}$ & $\mathrm{Mg}$ & $S$ & $\mathrm{U}-65^{\circ} \mathrm{C}$ & $\mathrm{C}$ \\
\hline 0,9 & 0,3 & 0,1 & 0,3 & 0,1 & 0,2 & 2,0 & 11,0 \\
\hline $\mathrm{Na}$ & $\mathrm{Cu}$ & $\mathrm{Fe}$ & $\mathrm{Mn}$ & $\mathrm{Zn}$ & $\mathrm{C} / \mathrm{N}$ & $\mathrm{pH}$ & MO \\
\hline 624 & $-{ }^{-m g ~ k}$ & $\begin{array}{r}\text { atural -- } \\
12103\end{array}$ & 204 & 53 & $12 / 1$ & $\begin{array}{l}\mathrm{CaCl}_{2} \\
5,3\end{array}$ & $\begin{array}{l}\% \text { ao natural } \\
20,0\end{array}$ \\
\hline
\end{tabular}

$\mathrm{U}=$ umidade; $\mathrm{MO}$ = matéria orgânica; $\mathrm{C} / \mathrm{N}$ = relação carbono e nitrogênio.

Tabela 3. Resultado da análise das características do solo de barranco (S) utilizada. Cassilândia-MS, 2015.

\begin{tabular}{|c|c|c|c|c|c|c|}
\hline $\begin{array}{l}P_{\text {resina }} \\
\mathrm{mg} \mathrm{dm}^{-3}\end{array}$ & 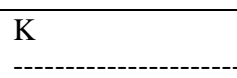 & $\mathrm{Ca}$ & $\begin{array}{c}\mathrm{Mg} \\
\mathrm{d}_{\mathrm{c}} \mathrm{dm}\end{array}$ & SB & CTC & $\mathrm{V} \%$ \\
\hline 4 & 0,6 & 7 & 3 & 11 & 50 & 22 \\
\hline $\begin{array}{l}\mathrm{pH} \\
\text { água }\end{array}$ & $\begin{array}{l}\text { Matéria orgânica } \\
\mathrm{g} \mathrm{dm}^{-3}\end{array}$ & B & $\mathrm{Cu}$ & $\begin{array}{l}\mathrm{Fe} \\
\mathrm{m}^{-3}\end{array}$ & $\mathrm{Mn}$ & $\mathrm{Zn}$ \\
\hline 4,6 & 6,0 & 0,21 & 0,50 & 15,0 & 8,3 & 0,1 \\
\hline
\end{tabular}



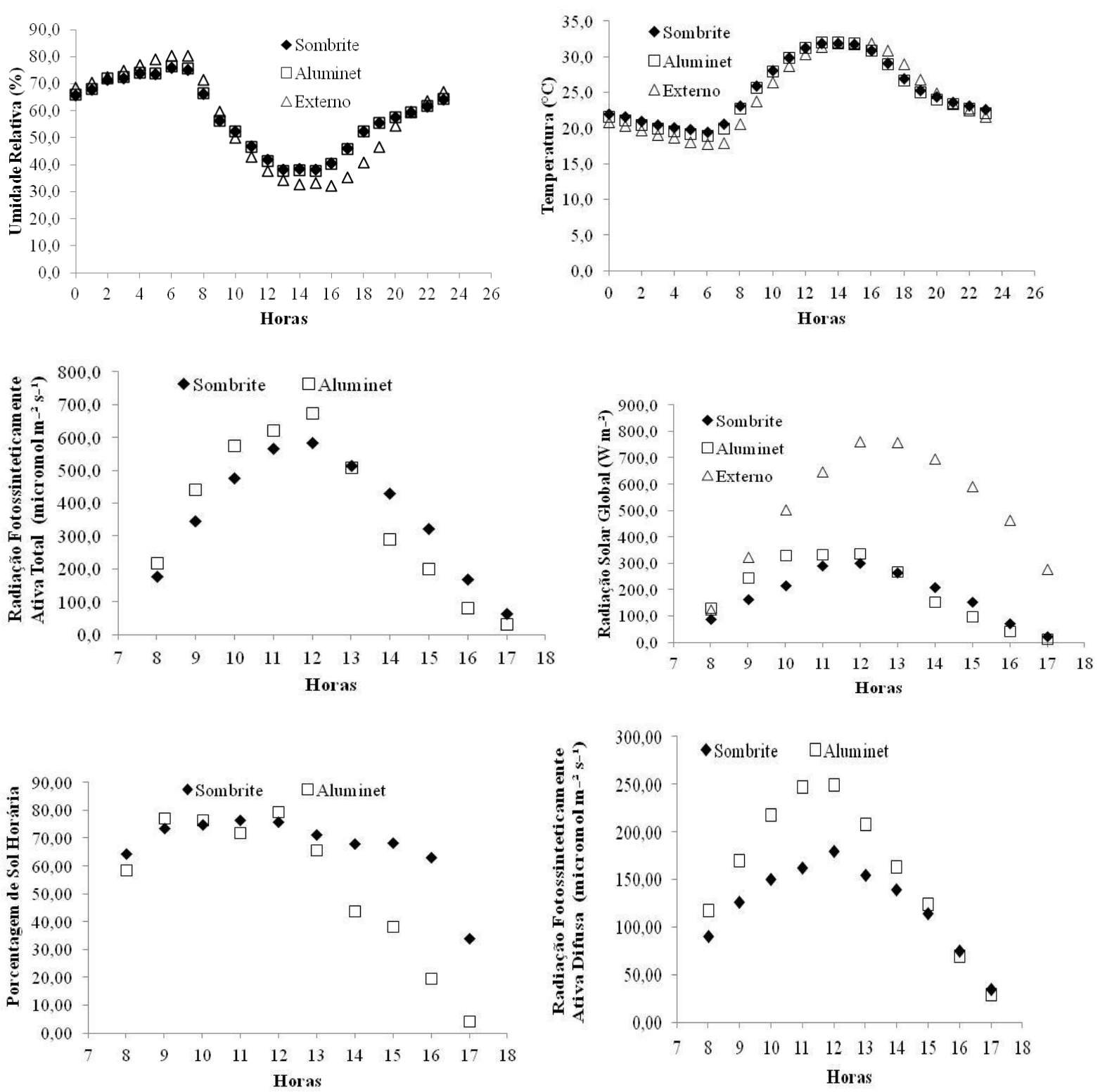

Figura 1. Médias horárias de temperatura do ar (a), Umidade relativa do ar (b), radiação solar global (c), radiação fotossinteticamente ativa total (d) e difusa (e), e a porcentagem de sol horária (f) registrados nos ambientes de cultivo e externo durante o período experimental.

Tabela 4. Valores médios de temperatura do ar $\left({ }^{\circ} \mathrm{C}\right)$, umidade relativa do ar $(\%)$, radiação solar global $\left(\mathrm{W} \mathrm{m}^{-2}\right)$, radiação fotossinteticamente ativa total $\left(\mu \mathrm{mol} \cdot \mathrm{m}^{-2} \cdot \mathrm{s}^{-1}\right)$, radiação fotossinteticamente ativa total e difusa $\left(\mu \mathrm{mol} . \mathrm{m}^{-2} \cdot \mathrm{s}^{-1}\right)$, e porcentagem de sol horária das 8 a 17 horas durante o período de experimento. Cassilândia-MS, 2015.

\begin{tabular}{|c|c|c|c|}
\hline Variáveis micrometeorológicos & Sombrite $\AA$ & Aluminet ${ }^{\circledR}$ & Externo \\
\hline Temperatura $\left({ }^{\circ} \mathrm{C}\right)$ & 25,24 & 24,96 & 24,54 \\
\hline Umidade relativa $(\%)$ & 57,89 & 57,93 & 56,77 \\
\hline Radiação solar global $\left(\mathrm{W} \mathrm{m}^{-2}\right)$ & 178,29 & 195,27 & 515,20 \\
\hline Radiação fotossinteticamente ativa total $\left(\mu \mathrm{mol} \mathrm{m} \mathrm{s}^{-2}\right)$ & 365,10 & 364,74 & - \\
\hline Radiação fotossinteticamente ativa difusa $\left(\mu \mathrm{mol} \mathrm{m} \mathrm{m}^{-2} \mathrm{~s}^{-1}\right)$ & 122,86 & 159,86 & - \\
\hline Porcentagem de Sol horária (\%) & 67,02 & 53,00 & - \\
\hline
\end{tabular}

\section{Resultados e Discussão}

Para o índice de velocidade de emergência (IVE), tanto os ambientes como os substratos não apresentaram diferenças significativas (Tabela 5). As diferentes intensidades de radiação (Figuras 1D, 1E e Tabela 4) não influenciaram a velocidade de emergência do maracujazeiro no presente estudo, pois as temperaturas e umidade estavam muito próximas (Figura 1A; Tabela 4). No telado Sombrite ${ }^{\circledR}$ foi verificada menor quantidade de radiação fotossinteticamente ativa difusa $\left(\mu \mathrm{mol} \mathrm{m}{ }^{-2} \mathrm{~s}^{-1}\right)$ (Figura 1E e Tabela 4). Porém, condição esta que não interferiu na emergência do maracujazeiro, 
diferente do observado por Freitas et al. (2015) a pleno sol que verificaram maior IVE em telados de tela simples, duplas e triplas do tipo sombrite, explicitando desta forma que quanto menor a disponibilidade de luz, menores foram os IVE. Os mesmos autores observaram, também, que a tela simples propiciou maior IVE que as telas duplas e triplas.

$\mathrm{Na}$ altura coletada aos 35 DAS no telado preto (Tabela 6) as maiores mudas foram observadas nos substratos S2, S3 e S7. No telado aluminizado as maiores mudas foram verificadas nos substratos $\mathrm{S} 1, \mathrm{~S} 2$, S7, S8 e S9 (Tabela 6). Na altura aos 50 DAS (Tabela 5) as maiores mudas estavam nos substratos S1, S2, S3, $\mathrm{S} 7, \mathrm{~S} 8, \mathrm{~S} 9$ e S10. Nos substratos em que se verificaram as maiores mudas, com maiores diâmetros (Tabela 5 e 6), a quantidade de esterco e/ou vermiculita utilizada foi em maiores proporções. A associação de esterco bovino e vermiculita foram determinantes para obtenção de mudas de maracujazeiro de maior qualidade, pois estes propiciaram nutrição adequada (Tabela 2), assim como manutenção das propriedades físicas, pois a vermiculita possui grande capacidade de aeração e retenção de água.

No presente estudo foi verificada a obtenção de mudas de alta qualidade com o uso de $50 \%$ de esterco bovino nos substratos, diferente do verificado por Costa et al. (2015) para o baruzeiro, Dias et al. (2009a) e Silva et al. (2009) para a mangabeira, Dias et al. (2009b) para o cafeeiro e Cavalcanti (2010) para o jambolão, cujos estudos recomendam a não utilizar mais que $30 \%$ de esterco bovino em substratos. Nos substratos que continham 20, 30 e 40\% de Bioplant ${ }^{\circledR}$ (S11, S12 e S13), assim como nos substratos que continham 30 e $40 \%$ de areia (S4 e S5) foram verificadas as menores plantas com os menores diâmetros (Tabela 5 e 6). Smiderle et al. (2001) observaram em substrato com 33,33\% de areia menor espaço poroso total, situação esta que no presente trabalho não forneceu condições adequadas ao crescimento do maracujazeiro.

O Bioplant ${ }^{\circledR}$, segundo o fabricante, possui em sua composição fibra de coco, casca de pinus, esterco, serragem, vermiculita, casca de arroz, cinza, gesso agrícola, carbonato de cálcio, magnésio, termofosfato magnesiano (yoorin) e aditivos (fertilizantes), no entanto, nos substratos com as maiores quantidades desse material não se observaram desenvolvimento adequado de fitomassas aéreas, radiculares e totais das plantas de jambolão.

Tal efeito negativo das maiores quantidades de areia e Bioplant $^{\circledR}$ nos substratos estudados, podem estar relacionados às características físicas e químicas desses componentes (SILVA; MENDONÇA, 2007). Alguns autores relatam que a utilização de Bioplant ${ }^{\circledR}$ como material de substrato na produção de mudas florestais apresentou resultados negativos. Alves et al. (2012) relatam que, para plântulas de Crateva tapia L., submetidas à temperatura de 20 a $30^{\circ} \mathrm{C}$, a utilização Bioplant $^{\circledR}$ não propiciou desenvolvimento radicular adequado. Borges et al. (2016) afirmam que, mesmo o Bioplant ${ }^{\circledR}$ suplementado com outros compostos como a vermiculita e o pó-de-coco na proporção de $20 \%$ e $40 \%$, não incrementou na altura de plantas de Eugenia calycina.

Tabela 5. Índice de velocidade de emergência (IVE), altura da muda aos 50 DAS (AP2) e relação altura e diâmetro aos 50 DAS (RAD) das mudas de maracujazeiro amarelo doce. Cassilândia, MS, 2015.

\begin{tabular}{cccc}
\hline Ambientes & IVE & AP2 & RAD \\
\hline Telado preto (A1) & $0,585 \mathrm{a}$ & $10,50 \mathrm{a}$ & $4,00 \mathrm{a}$ \\
Telado aluminizado (A2) & $0,595 \mathrm{a}$ & $9,75 \mathrm{~b}$ & $3,54 \mathrm{~b}$ \\
\hline Substratos & IVE & AP2 & RAD \\
\hline $\mathrm{S} 1=50 \% \mathrm{E}+30 \% \mathrm{~S}+10 \% \mathrm{~B}+10 \% \mathrm{~F}+0 \% \mathrm{~A}$ & $0,595 \mathrm{a}$ & $11,60 \mathrm{a}$ & $3,75 \mathrm{a}$ \\
$\mathrm{S} 2=40 \% \mathrm{E}+30 \% \mathrm{~S}+10 \% \mathrm{~B}+10 \% \mathrm{~F}+10 \% \mathrm{~A}$ & $0,578 \mathrm{a}$ & $11,96 \mathrm{a}$ & $3,84 \mathrm{a}$ \\
$\mathrm{S} 3=30 \% \mathrm{E}+30 \% \mathrm{~S}+10 \% \mathrm{~B}+10 \% \mathrm{~F}+20 \% \mathrm{~A}$ & $0,595 \mathrm{a}$ & $11,17 \mathrm{a}$ & $3,84 \mathrm{a}$ \\
$\mathrm{S} 4=20 \% \mathrm{E}+30 \% \mathrm{~S}+10 \% \mathrm{~B}+10 \% \mathrm{~F}+30 \% \mathrm{~A}$ & $0,574 \mathrm{a}$ & $8,98 \mathrm{~b}$ & $3,57 \mathrm{a}$ \\
$\mathrm{S} 5=10 \% \mathrm{E}+30 \% \mathrm{~S}+10 \% \mathrm{~B}+10 \% \mathrm{~F}+40 \% \mathrm{~A}$ & $0,581 \mathrm{a}$ & $9,65 \mathrm{~b}$ & $4,04 \mathrm{a}$ \\
$\mathrm{S} 6=50 \% \mathrm{E}+30 \% \mathrm{~S}+10 \% \mathrm{~B}+0 \% \mathrm{~F}+10 \% \mathrm{~A}$ & $0,511 \mathrm{a}$ & $9,63 \mathrm{~b}$ & $3,42 \mathrm{a}$ \\
$\mathrm{S} 7=30 \% \mathrm{E}+30 \% \mathrm{~S}+10 \% \mathrm{~B}+20 \% \mathrm{~F}+10 \% \mathrm{~A}$ & $0,611 \mathrm{a}$ & $10,99 \mathrm{a}$ & $3,99 \mathrm{a}$ \\
$\mathrm{S} 8=20 \% \mathrm{E}+30 \% \mathrm{~S}+10 \% \mathrm{~B}+30 \% \mathrm{~F}+10 \% \mathrm{~A}$ & $0,623 \mathrm{a}$ & $11,67 \mathrm{a}$ & $3,98 \mathrm{a}$ \\
$\mathrm{S} 9=10 \% \mathrm{E}+30 \% \mathrm{~S}+10 \% \mathrm{~B}+40 \% \mathrm{~F}+10 \% \mathrm{~A}$ & $0,617 \mathrm{a}$ & $10,55 \mathrm{a}$ & $3,98 \mathrm{a}$ \\
$\mathrm{S} 10=50 \% \mathrm{E}+30 \% \mathrm{~S}+0 \% \mathrm{~B}+10 \% \mathrm{~F}+10 \% \mathrm{~A}$ & $0,579 \mathrm{a}$ & $11,98 \mathrm{a}$ & $4,01 \mathrm{a}$ \\
$\mathrm{S} 11=30 \% \mathrm{E}+30 \% \mathrm{~S}+20 \% \mathrm{~B}+10 \% \mathrm{~F}+10 \% \mathrm{~A}$ & $0,594 \mathrm{a}$ & $9,55 \mathrm{~b}$ & $3,65 \mathrm{a}$ \\
$\mathrm{S} 12=20 \% \mathrm{E}+30 \% \mathrm{~S}+30 \% \mathrm{~B}+10 \% \mathrm{~F}+10 \% \mathrm{~A}$ & $0,593 \mathrm{a}$ & $9,39 \mathrm{~b}$ & $3,73 \mathrm{a}$ \\
$\mathrm{S} 13=10 \% \mathrm{E}+30 \% \mathrm{~S}+40 \% \mathrm{~B}+10 \% \mathrm{~F}+10 \% \mathrm{~A}$ & $0,622 \mathrm{a}$ & $4,54 \mathrm{c}$ & $3,25 \mathrm{a}$ \\
\hline CV $(\%)$ & 18,55 & 15,77 & 14,86 \\
\hline
\end{tabular}

Letras iguais não diferem pelo teste de Scott-Knott para os substratos e pelo teste $\mathrm{F}$ para os ambientes, ambos a 5\% de probabilidade. $\mathrm{E}=$ esterco bovino; $\mathrm{S}=$ solo de barranco; $\mathrm{B}=$ bioplant ${ }^{\mathrm{a}} ; \mathrm{F}=$ vermiculita super fina; $\mathrm{A}=$ areia. 
Tabela 6. Diâmetro do colo (DC) aos 50 DAS e altura da muda aos 35 DAS (AP1) das mudas de maracujazeiro amarelo doce. Cassilândia, MS, 2015.

\begin{tabular}{crrcc}
\hline & \multicolumn{2}{c}{$\begin{array}{c}\text { Diâmetro do colo DC } \\
(\mathrm{mm})\end{array}$} & \multicolumn{2}{c}{$\begin{array}{c}\text { Altura das mudas aos 35 DAS } \\
(\mathrm{cm})\end{array}$} \\
\hline & Telado preto & Telado aluminizado & Telado preto & Telado aluminizado \\
\hline $\mathrm{S} 1=50 \% \mathrm{E}+30 \% \mathrm{~S}+10 \% \mathrm{~B}+10 \% \mathrm{~F}+0 \% \mathrm{~A}$ & $2,98 \mathrm{aA}$ & $3,20 \mathrm{aA}$ & $7,91 \mathrm{aB}$ & $8,48 \mathrm{aA}$ \\
$\mathrm{S} 2=40 \% \mathrm{E}+30 \% \mathrm{~S}+10 \% \mathrm{~B}+10 \% \mathrm{~F}+10 \% \mathrm{~A}$ & $3,06 \mathrm{aA}$ & $3,16 \mathrm{aA}$ & $9,81 \mathrm{aA}$ & $7,10 \mathrm{bA}$ \\
$\mathrm{S} 3=30 \% \mathrm{E}+30 \% \mathrm{~S}+10 \% \mathrm{~B}+10 \% \mathrm{~F}+20 \% \mathrm{~A}$ & $3,03 \mathrm{aA}$ & $2,80 \mathrm{aB}$ & $9,01 \mathrm{aA}$ & $6,17 \mathrm{bB}$ \\
$\mathrm{S} 4=20 \% \mathrm{E}+30 \% \mathrm{~S}+10 \% \mathrm{~B}+10 \% \mathrm{~F}+30 \% \mathrm{~A}$ & $2,40 \mathrm{aB}$ & $2,65 \mathrm{aB}$ & $6,98 \mathrm{aB}$ & $5,92 \mathrm{aB}$ \\
$\mathrm{S} 5=10 \% \mathrm{E}+30 \% \mathrm{~S}+10 \% \mathrm{~B}+10 \% \mathrm{~F}+40 \% \mathrm{~A}$ & $2,48 \mathrm{aB}$ & $2,29 \mathrm{aC}$ & $7,78 \mathrm{aB}$ & $5,86 \mathrm{bB}$ \\
$\mathrm{S} 6=50 \% \mathrm{E}+30 \% \mathrm{~S}+10 \% \mathrm{~B}+0 \% \mathrm{~F}+10 \% \mathrm{~A}$ & $2,57 \mathrm{bB}$ & $3,08 \mathrm{aA}$ & $7,12 \mathrm{aB}$ & $6,60 \mathrm{aB}$ \\
$\mathrm{S} 7=30 \% \mathrm{E}+30 \% \mathrm{~S}+10 \% \mathrm{~B}+20 \% \mathrm{~F}+10 \% \mathrm{~A}$ & $2,85 \mathrm{aA}$ & $2,64 \mathrm{aB}$ & $8,99 \mathrm{aA}$ & $7,39 \mathrm{bA}$ \\
$\mathrm{S} 8=20 \% \mathrm{E}+30 \% \mathrm{~S}+10 \% \mathrm{~B}+30 \% \mathrm{~F}+10 \% \mathrm{~A}$ & $2,83 \mathrm{aA}$ & $3,06 \mathrm{aA}$ & $7,71 \mathrm{aB}$ & $8,24 \mathrm{aA}$ \\
$\mathrm{S} 9=10 \% \mathrm{E}+30 \% \mathrm{~S}+10 \% \mathrm{~B}+40 \% \mathrm{~F}+10 \% \mathrm{~A}$ & $2,56 \mathrm{aB}$ & $2,76 \mathrm{aB}$ & $7,56 \mathrm{aB}$ & $7,13 \mathrm{aA}$ \\
$\mathrm{S} 10=50 \% \mathrm{E}+30 \% \mathrm{~S}+0 \% \mathrm{~B}+10 \% \mathrm{~F}+10 \% \mathrm{~A}$ & $2,77 \mathrm{bA}$ & $3,25 \mathrm{aA}$ & $8,27 \mathrm{aB}$ & $7,99 \mathrm{aA}$ \\
$\mathrm{S} 11=30 \% \mathrm{E}+30 \% \mathrm{~S}+20 \% \mathrm{~B}+10 \% \mathrm{~F}+10 \% \mathrm{~A}$ & $2,61 \mathrm{aB}$ & $2,68 \mathrm{aB}$ & $7,71 \mathrm{aB}$ & $5,88 \mathrm{bB}$ \\
$\mathrm{S} 12=20 \% \mathrm{E}+30 \% \mathrm{~S}+30 \% \mathrm{~B}+10 \% \mathrm{~F}+10 \% \mathrm{~A}$ & $2,38 \mathrm{bB}$ & $2,70 \mathrm{aB}$ & $6,93 \mathrm{aB}$ & $6,26 \mathrm{aB}$ \\
$\mathrm{S} 13=10 \% \mathrm{E}+30 \% \mathrm{~S}+40 \% \mathrm{~B}+10 \% \mathrm{~F}+10 \% \mathrm{~A}$ & $1,32 \mathrm{aC}$ & $1,49 \mathrm{aD}$ & $3,63 \mathrm{aC}$ & $3,59 \mathrm{aC}$ \\
\hline $\mathrm{CV} \%)$ & \multicolumn{4}{c}{12,96} \\
\hline
\end{tabular}

Letras iguais minúsculas na linha e maiúsculas nas colunas não diferem pelo teste de Scott-Knott para os substratos e pelo teste $\mathrm{F}$ para os ambientes,

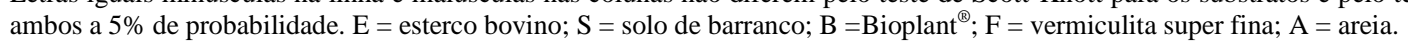

Dutra et al. (2012) relatam resultados semelhantes aos obtidos neste trabalho; na produção de mudas de Copaíba onde o composto Bioplant $^{\circledR}$ apresentou resultados inferiores para massa seca foliar, massa seca total e ralação massa seca foliar, comparados às proporções de vermiculita e casca de arroz carbonizado.

A melhor relação entre a altura da muda e o seu diâmetro do colo (Tabela 5), assim como os maiores diâmetros das mudas em alguns substratos (Tabela 6), foram verificados no ambiente com tela aluminizada. No ambiente de tela preta pode ter ocorrido uma tendência ao estiolamento, com plantas maiores e menores diâmetros para alguns substratos. No ambiente de tela aluminizada verificou-se maiores quantidades de radiação fotossinteticamente ativa total e difusa (Figuras $1 \mathrm{D}$ e 1E; Tabela 4), bem como menor porcentagem de exposição diária ao sol (Figura 1F e Tabela 4). Tais fatores ambientais contribuíram para menor relação altura/diâmetro e maior incremento em diâmetro nas mudas de maracujazeiro. Costa et al. (2009, 2010a), testando 4 tipos de ambientes protegidos de estrutura de madeira, na formação de mudas de maracujazeiro, não verificaram diferenças entre os telados com telas de cor preta e aluminizado (dimensões: 5,0 m x 5,0 m x 2,5 m, ambos com fechamentos laterais em $90^{\circ}$ de inclinação).

\section{Conclusões}

As melhores mudas de maracujazeiro amarelo doce foram formadas em substratos compostos com grande quantidade de esterco e/ou vermiculita e em menor proporção de areia e Bioplant ${ }^{\circledR}$.
Substratos com elevadas quantidades de Bioplant ${ }^{\circledR}$ ou areia não são indicados à formação de mudas de maracujazeiro

O telado aluminizado propiciou condições para obtenção de mudas de maior qualidade, com maior diâmetro em alguns substratos, e menor relação altura/diâmetro.

\section{Agradecimentos}

À Coordenação de Aperfeiçoamento de Pessoal de Nível Superior (CAPES) e À Fundação de Apoio ao Desenvolvimento do Ensino, Ciência e Tecnologia do Estado de Mato Grosso do Sul (FUNDECT) pelo apoio financeiro e pela concessão de bolsas. Ao Programa de Apoio a Núcleos Emergentes (PRONEM-MS) Edital Chamada FUNDECT/CNPq N ${ }^{\circ}$ 15/2014; TERMO DE OUTORGA: 080/2015 SIAFEM: 024367. A FUNDECT/PPP (Programa Primeiros Projetos) Edital 05/2011, Proc. No 23/200.647/2012, TERMO DE OUTORGA: 0152/12 SIAFEM: 020865.

\section{Referências Bibliográficas}

ALMEIDA, A. Composto de lixo urbano na composição química do solo e seus efeitos no desenvolvimento de mudas de maracujazeiro amarelo. Revista de Biociências, TaubatéSP, v. 9, n. 2, p. 07-15, 2003.

ALVES, E. U.; MOURA, S. S. S.; MOURA, M. F.; GUEDES, R. S.; ESTRELA, F. A. Germinação e vigor de sementes de Crateava tapia $\mathrm{L}$. em diferentes substratos e temperaturas. Revista Brasileira de Fruticultura, Jaboticabal-SP, v. 34, n.4, p. 1208-1215, 2012. 
BANZATTO, D. A.; KRONKA, S. N. Experimentação agrícola. $3^{\text {a }}$. ed. Jaboticabal-SP: Funep, 2013. 237 p.

BIASI, L. A.; BILIA, D. A. C.; SÃO JOSÉ, A. R.; FORNASIERI, J. L.; MINAMI, K. Efeito de misturas de turfa e bagaço-de-cana sobre a produção de mudas de maracujá e tomate. Scientia Agricola, Piracicaba-SP, v. 52, n. 2, p. 239242, 1995.

BORGES, K. C. F.; SANTANA, D. G.; LOPES, S. W.; PEREIRA, V. J. Coloração do fruto e substrato na emergência e no crescimento de plantas de Eugenia calycinas Cambess. Floresta e Ambiente, Seropédica-RJ, v. 23, n. 4, p. 72-77, 2016.

CAVALCANTI, N. B. Crescimento inicial de plantas de Jambolão (Syzygium jambolanum Lam.) em diferentes substratos. Engenharia Ambiental, Espírito Santo do PinhalSP, v. 8, n. 4, p. 164-182, 2011.

COSTA, E.; RODRIGUES, E. T.; ALVES, V. B.; SANTOS, L. C. R.; VIEIRA, L. C. R. Efeitos da ambiência, recipientes e substratos no desenvolvimento de mudas de maracujazeiroamarelo em Aquidauana-MS. Revista Brasileira de Fruticultura, Jaboticabal-SP, v. 31, n. 1, p. 236-244, 2009.

COSTA, E.; SANTOS, L. C. R.; CARVALHO, C.; LEAL, P. A. M.; GOMES, V. A. Volumes de substratos comerciais, solo e composto orgânico afetando a formação de mudas de maracujazeiro-amarelo em diferentes ambientes de cultivo. Revista Ceres, Viçosa-MG, v. 58, n. 2, p. 216-222, 2011.

COSTA, E.; LEAL, P. A. M.; SANTOS, L. C. R.; VIEIRA, L. C. R. Ambientes de cultivo, recipientes e substratos na produção de biomassa foliar e radicular em mudas de maracujazeiro amarelo em Aquidauana-MS. Ciência e Agrotecnologia, Lavras-MG, v. 34, n. 2, p. 461-467, 2010a.

COSTA, E.; LEAL, P. A. M.; SASSAQUI, A. R.; GOMES, V. A. Doses de composto orgânico comercial na composição de substratos para a produção de mudas de maracujazeiro em diferentes tipos de cultivo protegido. Engenharia Agrícola, Jaboticabal-SP, v. 30, n. 5, p. 776-787, 2010 b.

COSTA, E.; DIAS, J. G.; LOPES, K. G.; BINOTTI, F. F. S.; CARDOSO, E. D. Telas de Sombreamento e Substratos na Produção de Mudas de Dipteryx alata Vog.. FLORAM . Revista Floresta e Ambiente, Seropédica-RJ, v. 22, n. 3, p. 416-425, 2015.

DIAS, T. J.; PEREIRA, W. E.; CAVACANTE, L. F.; RAPOSO, R. W. C.; FREIRE, J. L. O. Desenvolvimento e qualidade nutricional de mudas de mangabeiras cultivadas em substratos contendo fibra de coco e adubação fosfatada. Revista Brasileira de Fruticultura, Jaboticabal-SP, v. 31, n. 2, p. 512-523, 2009a.

DIAS, R.; MELO, B.; RUFINO, M. A.; SILVEIRA, D. L.; MORAIS, T. P. Fontes e proporção de material orgânico para a produção de mudas de cafeeiro em tubetes. Ciência e Agrotecnologia, Lavras-MG, v. 33, n. 3, p. 758-764, 2009 b.

DUTRA, T. R.; GRAZZIOTTI, P. H.; SANTANA, R. C; MASSAD, M. D. Desenvolvimento inicial de mudas de copaíba sob diferentes níveis de sombreamento e substratos. Revista Ciência Agronômica, Fortaleza-CE, v. 43, n. 2, p. 321-329, 2012.
FREITAS, A. R.; LOPES, J. C.; ALEXANDRE, R. S.; VENANCIO, L. P.; ZANOTTI, R. F. Emergência e crescimento de mudas de maracujá doce em função de lodo de esgoto e luz. Comunicata Scientiae, Vitória-ES, v. 6, n. 2, p. 234-240, 2015.

MENDONCA, V.; RAMOS, J. D.; GONTIJO, T. C. A.; MARTINS, P. C. C.; DANTAS, D. J.; PIO, R.; ARRUDA, N. A. A. Osmocote e substratos alternativos na produção de mudas de maracujazeiro-amarelo. Ciência e Agrotecnologia, Lavras-MG, v. 28, n. 4, p. 799-806, 2004.

MENDONCA, V.; ORBES, M. Y.; ARRUDA, N. A. A.; RAMOS, J. D.; TEIXEIRA, G. A.; SOUZA, H. A. Qualidade de mudas de maracujazeiro-amarelo formadas em substratos com diferentes níveis de Lithothamniun. Ciência e Agrotecnologia, Lavras-MG, v. 30, n. 5, p. 900-906, 2006.

MENDONCA, V.; RAMOS, J. D.; RUFINI, J. C. M.; PIO, R.; CARRIJO, E. P.; GONTIJO, T. C. A. Diferentes substratos e ambientes na formação de mudas de maracujazeiro-amarelo. Revista Científica Rural, Bagé-RS, v. 10, n. 2, p. 10-15, 2005.

NEGREIROS, J. R. S.; ÁLVARES, V. S.; BRAGA, L. R.; BRUCKNER, C. H. Diferentes substratos na formação de mudas de maracujazeiro-amarelo. Revista Ceres, Viçosa-MG, v. 51, n. 294, p. 243-249, 2004.

OLIVEIRA, R. P.; SCIVITTARO, W. B.; VASCONCELLOS, L. A. B. C. Avaliação de mudas de maracujazeiro em função do substrato e do tipo de bandeja. Scientia Agricola, Piracicaba-SP, v. 50, n. 2, p. 261-266, 1993.

PIO, R.; GONTIJO, T. C. A.; RAMOS, J. D.; CARRIJO, E. P.; TOLEDO, M.; VISIOLI, E. L.; TOMASETTO, F. Produção de mudas de maracujazeiro amarelo em diferentes substratos. Revista Brasileira de Agrociência, Pelotas-RS, v. 10, n. 4, p. 523-525, 2004.

RIBEIRO, M. C. C.; MORAIS, M. J. A.; SOUSA, A. H.; LINHARES, P. C. F.; BARROS JUNIOR, A. P. Produção de mudas de maracujá-amarelo com diferentes substratos e recipientes. Caatinga, Mossoró-RN, v. 18, n. 3, p.155-158, 2005.

SILVA, R. P.; PEIXOTO, J. R.; JUNQUEIRA, N. T. V. Influência de diversos substratos no desenvolvimento de muda de maracujazeiro-azedo (Passiflora edulis Sims f. flavicarpa Deg). Revista Brasileira de Fruticultura, Jaboticabal-SP, v. 23, n. 2, p. 377-381, 2001.

SILVA, E. P.; MARUYAMA W. I.; OLIVEIRA, A. C.; BARDIVIESSO, D. M. Efeito de diferentes substratos na produção de mudas de mangabeira (Hancornia speciosa $\mathrm{G}$ ). Revista Brasileira de Fruticultura, Jaboticabal-SP, v. 31, n. 3, p. 925-929, 2009.

SILVA, E. A.; MARUYAMA, W. I.; MENDONÇA, V.; FRANCISCO, M. G. S.; BARDIVIESSO, D. M.; TOSTA, M. S. Composição de substratos e tamanho de recipientes na produção e qualidade das mudas de maracujazeiro 'amarelo'. Ciência e Agrotecnologia, Lavras-MG, v. 34, n. 3, p. 588$595,2010$.

SILVA, I. R.; MENDONÇA, E. S. Matéria orgânica no solo. In: NOVAES, R. F.; ALVAREZ, V. H. V.; BARROS, N. F.; 
FONTES, R. L. F.; CANTARUTTI, R. B.; NEVES, J. C. L. Fertilidade do solo. Viçosa-MG: Sociedade Brasileira de Ciência do Solo, 2007. p. 275-374.

SMIDERLE, O. J.; SALIBE, A. B.; HAYASHI, A. H.; MINAMI, K. Produção de mudas de alface, pepino e pimentão em substratos combinando areia, solo e Plantmax ${ }^{\circledR}$. Horticultura Brasileira, Brasília-DF, v. 19, n. 3, p. 253-257, 2001.

VERDIAL, M. F, L.; SANTOS, M.; TESSARIOLI NETO, J. Métodos de formação de mudas de maracujazeiro amarelo. Scentia agricola, Piracicaba-SP, v. 57, n. 4, p. 795-798, 2000.
WAGNER JÚNIOR, A.; ALEXANDRE, R. S.; NEGREIRO, J. R.; PIMENTEL, L. D.; COSTA E SILVA, J. O.; BRUCKNER, C. H. Influência do substrato na germinação e desenvolvimento inicial de plantas de maracujazeiro amarelo (Passiflora edulis Sims f. flavicarpa Deg). Ciência e Agrotecnologia, Lavras-MG, v. 30, n. 4, 2006.

ZANELLA, F.; SONCELA, R.; LIMA, A. L. S. Formação de mudas de maracujazeiro "amarelo" sob níveis de sombreamento em Ji-Paraná/RO. Ciência e Agrotecnologia, Lavras-MG, v. 30, n 5, p. 880-884, 2006. 